\title{
Evaluación de la efectividad de altas dosis de riboflavina en la profilaxis de la migraña
}

Effectiveness of high-dose riboflavin in migraine prophylaxis. Schoenen J, Jacquy J, Lenaerts M, Neurology 1998; 50: 466-470.

\section{Objetivo}

Evaluar la eficacia de la riboflavina (vitamina B2) en la profilaxis de la migraña.

\section{Diseño}

Ensayo doble ciego y randomizado de tres meses de duración de dos grupos paralelos de pacientes tratados diariamente con $400 \mathrm{mg}$ de riboflavina oral versus placebo.

\section{Lugar}

Estudio multicéntrico realizado en 6 centros de Bélgica y Luxenburgo.

\section{Pacientes}

Entre marzo de 1995 y marzo de 1996 se reclutaron 55 pacientes de entre 18 y 65 años con migraña (con aura o sin ella) de acuerdo a los criterios diagnósticos de la Sociedad Internacional de Cefaleas. Los pacientes debian tener historia de migraña de al menos un año de evolución, con 2 a 8 ataques mensuales y no más de 5 días de intervalo entre los episodios. Se excluyeron aquellos pacientes con consumo excesivo de analgésicos y derivados ergotamínicos o con patología orgánica o psiquiátrica asociadas. Las mujeres debieron utilizar métodos anticonceptivos adecuados.

Cada paciente debió completar un diario en el que registraba la severidad y duración de cada ataque, la presencia simultánea de náuseas y vómitos y la cantidad de medicación abortiva requerida (tratamiento del dolor en agudo).

\section{Intervención}

En la primera visita los participantes recibieron placebo por un mes y en la segunda visita fueron randomizados a recibir placebo $0400 \mathrm{mg}$ de riboflavina por día sólo si habían presentado al menos un ataque de migraña en el mes precedente.

\section{Medición de resultados principales}

El resultado principal se definió como cambio en la frecuencia de los ataques de migraña comparando los meses 1 (placebo) y 4 (fin del tratamiento). Se consideraron como respondedores a aquellos pacientes que tuvieron una mejoría igual o superior al $50 \%$.

\section{Resultados principales}

El tratamiento diario con $400 \mathrm{mg}$ de riboflavina durante 3 meses fue superior al placebo para reducir la frecuencia de los ataques de migraña. La tasa de respondedores fue mayor en el grupo tratado con riboflavina ( $56 \%$ vs. $19 \%, p=0.01$ ). En este grupo también se observó una mayor tasa de respuesta al considerar la reducción del número de días con migraña ( $59 \%$ vs. $15 \%, p=0.002$ ) y el índice migrañoso, medido como días de cefalea + grado de severidad $(41 \%$ vs $8 \%, p=$ 0.01 ).

La superioridad de la riboflavina sobre el placebo fue marginal en la mejoría de la severidad y duración del dolor, en el uso de drogas abortivas y en la reducción de síntomas acompañantes (náuseas y vómitos).

No se detectaron efectos adversos de seriedad.

\section{Conclusiones}

El uso de roboflavina resulta una opción interesante para el manejo profiláctico de la migraña.

Palabras clave: migraña, profilaxis, riboflavina.

\section{COMENTARIO}

Se estima que la prevalencia de la migraña es del.18\% en las mujeres y del $6 \%$ en los hombres. ${ }^{1}$

En este ensayo doble ciego y randomizado de tres meses de duración, se comparó el efecto de $400 \mathrm{mg}$ diarios de riboflavina oral (intervención) versus placebo como tratamiento profiláctico de la migraña demostrándose la superioridad de la rivoflabina. De acuerdo a los resultados, el NNT para reducir la frecuencia de los ataques es de 2.8 y para reducir el número de días con cefalea es de 2.3 , lo que transforma a la vitamina $B$ en una opción muy seductora para el manejo de los pacientes migrañosos (bajo NNT y efectos adversos casi nulos).

Sin embargo, es importante resaltar algunos puntos. Uno de ellos es que la droga utilizada fue comparada con placebo, a pesar de que existen otras drogas con eficacia demostrada en la profilaxis de esta entidad (beta bloqueantes, amitriptilina, etc.)..$^{2,3}$

Por otro lado, habitualmente se recomienda prolongar el tratamiento profiláctico de la migraña durante los 6 meses siguientes a la mejoría de los síntomas. En este caso el estudio duró sólo 3 meses y se desconoce cuál es el efecto de la rivoflabina transcurrido ese lapso.

Otro punto a considerar es que la vitamina B2 no parece tener efecto sobre los síntomas migrañosos que con frecuencia se asocian a la cefalea y que pueden ser tan molestos como ésta (náuseas y vómitos), aunque los resultados no pueden tomarse como definitivos ya que el estudio no fue diseñado para evaluar este punto.

Finalmente, en la actualidad no se dispone en el mercado de ninguna forma comercial que contenga sólo vitamina B2. Existen compuestos polivitamínicos con concentraciones de riboflavina considerablemente menores a las utilizadas en este estudio (2 a $15 \mathrm{mg} /$ dosis) por lo que debería solicitarse su preparación especial en el caso de decidir su uso. En definitiva, este trabajo resulta útil porque introduce una nueva droga a considerar en la investigación del manejo de la migraña, sin embargo, deberían realizarse estudios más prolongados y comparando el uso de la riboflavina con el de otras drogas con eficacia profiláctica demostrada, antes de generalizar en la práctica diaria la utilización de vitamina B2 con esta indicación.

Dra. Paula Carrete Unidad de medicina familiar y Preventiva. Hospital Italiano de Buenos Aires.

\section{Referencias}

1: Stewart WF et al. Migraine prevalence. A review of papulation-based studies. Neurology 1994;44 (suppl 4): S17-S23

2. Silberstein SD et al. Overview of diagnosis and treatment of migraine. Neurology 1994: 44 (10 suppl 7): S6-S16.

3. Noble $S$ et al. Drug treatment of migraine: Part II. Preventive therapy. Fam Physician 56; 9:2279-86 